\title{
Covid-19 driven advances in automation and artificial intelligence risk exacerbating economic inequality
}

\author{
Anton Korinek and Joseph E Stiglitz make the case for a deliberate effort to steer technological \\ advances in a direction that enhances the role of human workers
}

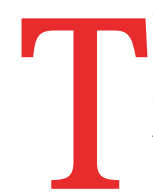
he covid-19 pandemic has necessitated interventions that reduce physical contact among people, with dire effects on our economy. By some estimates, a quarter of all jobs in the economy require physical interaction and are thus directly affected by the pandemic. This is highly visible in the medical sector, where workers and patients often come into close contact with each other and risk transmitting disease. In several countries medical workers have experienced some of the highest incidences of covid-19. Moreover, as patients were advised to postpone non-essential visits and procedures, medical providers in many countries have also experienced tremendous income losses. ${ }^{1}$

In economic language, covid-19 has added a "shadow cost" on labour that requires proximity. This shadow cost reflects the dollar equivalent of all the costs associated with the increased risk of disease transmission, including the costs of the adaptations required for covid-19. It consists of losses of both quality adjusted life days from increased morbidity and quality adjusted life years

\section{KEY MESSAGES}

- The covid-19 pandemic has increased the risk and raised the cost of direct physical contact between humans, as is particularly visible in healthcare

- This has accelerated advances in AI and other forms of automation to decrease physical contact and mitigate the risk of disease transmission

- These technological advances benefit technologists but could reduce labour demand more broadly and slow wage growth, increasing inequality between workers and the owners of technology

- These forces can be counteracted by intentionally steering technological progress in AI to complement labour, increasing its productivity from increased mortality, as well as the cost of measures to reduce these risks, such as extra protective equipment and distancing measures for workers. Some sectors will incur increased costs from changing the physical arrangements in which production and other interactions occur so that there can be social distancing. It is, of course, understandable that we take these measures to reduce the spread of the disease: by some estimates, the social cost of one additional case of covid-19 over the course of the pandemic is $\$ 56000$ (£40 000; €46000) to $\$ 111000$. $^{2}$

This shadow cost on labour is also accelerating the development and adoption of new technologies to automate human work. One example is the increasing use of telemedicine. Telemedicine is currently provided in a way that changes the format of delivery of care but leaves the role of doctors largely unchanged. However, it reduces the need for workers who provide ancillary services and who typically have lower wages than doctors-for example, front office or cleaning staff-thus increasing inequality. Moreover, going forward, it may also make it possible to provide medical services from other countries, which has hitherto been difficult, and hence reduce demand for doctors in high income countries. $^{3}$

Complementary investments, for example internet connected devices such as thermometers, fingertip pulse oximeters, blood pressure cuffs, digital stethoscopes, and electrocardiography devices could further revolutionise the delivery of medical care and may also reduce demand for nurses. ${ }^{45}$ Such technologies have already made it possible to establish "virtual wards" for patients with covid-19. ${ }^{6}$ But even once covid-19 is controlled, medical providers will take into account the risk of future pandemics when choosing which technologies to invest in. Looking further ahead, technologies powered by artificial intelligence (AI), such as Babylon Health's chatbot, foreshadow a possible future in which medical functions traditionally done by doctors may also be automated. This would reduce labour demand and generate a whole new set of potential problems. ${ }^{7}$

In the past, cybersecurity risks such as computer viruses have held back automation, especially in the medical sector, in which privacy and security are of particular concern. It is ironic that a human virus is now levelling the playing field and forcing automation because it has lessened the appetite for employing humans.

These developments have the potential to reduce labour demand and wages across the economy, including in healthcare. However, making labour redundant is not inevitable. Technological progress in AI and related fields can be steered so that the benefits of advances in technology are widely shared.

\section{Al, automation, and labour demand}

The fear of job losses has accompanied technological progress since the Industrial Revolution. ${ }^{8}$ The history of progress has been one of relentless churning in the labour market, whereby progress made old jobs redundant and created new ones. This churning has always been painful for displaced workers, but economists used to believe that the new jobs created by progress would be pay better than the ones that became redundant so that progress would make workers better off on balance, once they had gone through the adjustment. ${ }^{9}$

The most useful way to analyse the effects of a new technology on labour markets is not to look at whether it destroys jobs in the short term-many technologies have done so, even though they turned out to be beneficial for workers in the long run. Instead, it is most useful to categorise the effects of technological progress according to whether they are labour using or labour saving-that is, whether they increase or decrease overall demand for labour at given wages and prices. For example, automating many of the processes involved in medical consultations, as in the example 
of telemedicine, is likely to be labour saving, whereas new medical treatments to improve patients' health are likely to be labour using if they are performed by humans. ${ }^{10}$ In the long run, as markets adjust, changes in labour demand are mainly reflected in wages not in the number of jobs created or lost.

Overall, technological progress since the Industrial Revolution has been labour using-it increased labour demand by leaps and bounds, leading to a massive increase in average wages and material wealth in advanced countries. The reason was that innovation has increased the productivity of workers-making them able to produce more per hour-rather than replacing labour with robots.

However, more recently, the economic picture has been less benign: a substantial proportion of workers in the US-for example, production and non-supervisory workers-earn lower wages now (when adjusted for inflation) than in the 1970 s. $^{11}$ Moreover, although it is not clear whether this finding holds in the rest of the world, the share of economic output in the US going to workers rather than the owners of capital has declined from $65 \%$ to less than $60 \%$ over the past half century. ${ }^{12}{ }^{13}$ Lower skilled workers have been the most affected. Many recent automation technologies have displaced human workers from their jobs in a way that reduced overall demand for human labour. ${ }^{14}$

\section{Wealth distribution}

Advances in AI may contribute to more shared prosperity, ${ }^{6}$ but there is also a risk that they accelerate the trend of the past four decades. The defining attribute of $\mathrm{AI}$ is to automate the last domain in which human workers had a comparative advantage over machines-our thinking and learning. ${ }^{15}$ And if the covid-19 pandemic adds extra incentives for labour saving innovation, the economic effects would be even more painful than in past episodes of technological progress. When the economy is expanding and progress is biased against labour, workers may still experience modest increases in their incomes even though the relative share of output that they may earn is declining. However, at a time when economic output across the globe is falling because of the effects of covid-19, a decline in the relative share of output earned by workers implies that their incomes are falling at faster rates than the rest of the economy. And unskilled manual workers who are at the lower rungs of the earnings distribution are likely to be most severely affected.
An additional aspect of digital technologies such as AI is that they generate what is often called a "superstar" phenomenon, which may lead to further increases in inequality. Digital technologies can be deployed at almost negligible cost once they have been developed. ${ }^{16}$ They therefore give rise to natural monopolies, leading to dominant market positions whereby superstar firms serve a large fraction of the market-either because they are better than any competitors or because no one even attempts to duplicate their efforts and compete. These superstar effects are well known from entertainment industries. In the music industry, for example, the superstars have hundreds of millions of fans and reap in proportionate rewards, but the incomes of musicians further down the list decline quickly. Most of the rewards flow to the top. And empirical work documents that these superstar effects have played an important role in the rise in inequality in recent decades. ${ }^{17}$

A similar mechanism may soon apply in medicine, accelerated by the covid-19 pandemic. A commonly cited example is radiology. If one of the world's top medical imaging companies develops an AI system that can read and robustly interpret mammograms better than humans, it would become the "superstar" in the sector and would displace the task of reading mammograms for thousands of radiologists. Since the cost of processing an additional set of images is close to zero, any earnings after the initial investment in the system has been recouped would earn high profit margins, and the company is likely to reap substantial economic benefits, at least as long as its intellectual property is protected by patents or trade secrets. (The design of the intellectual property regime is an important determinant of the extent of the inequality generated by the economic transformations discussed here.) The more widespread such diagnostic and decision making tools become, the more the medical sector will turn into a superstar industry.

\section{Mitigating medical Al superstars}

Economic forces are continuing to drive rapid advances in AI, and covid-19 is adding strong tailwinds to these forces. The task now is to shape the forms that these advances will take to ensure that their effect on both patients and medical workers is desirable. The stakes are high since the choices that we make now will have long lasting effects.

We have a good sense of what happens at one extreme: if the direction of progress is determined purely by market forces without regard for shared human wellbeing, our technological future will be shaped by the shortcomings and failures of the market. ${ }^{1518}$

Markets may provide a force towards efficiency but are blind to distributional concerns, such as the deleterious consequences of labour saving progress or the superstar phenomenon. Responsible decision makers should pursue technologies that maintain an active role for humans and preserve a role for medical workers of all educational levels. For example, medical AI systems can be designed to be human centred tools that provide decision support or they can be designed to automate away human tasks. ${ }^{19}$ They should also focus on providing high quality care and value to patients with limited financial means rather than just serving patients according to their ability to pay.

Market failures are pervasive in both innovation and healthcare, and even more so at the intersection of the two. Markets encourage incremental advances that may not provide much value to society. They do not adequately provide incentives for larger scale breakthroughs that are most socially beneficial. And as the covid-19 pandemic has shown, they undervalue the benefits of preventive actions, including preventive actions against small probability but existential risks.

Market failures are sometimes exacerbated by government policies, which increase the cost of labour relative to capital, disadvantaging humans relative to machines. Examples include the low taxes on capital (especially capital gains) relative to labour and the artificially low interest rates that have prevailed since the 2008 financial crisis (although low interest rates are also boosting aggregate demand, which is beneficial for workers).

Our institutions and norms interact in important ways with market incentives for technological progress. Most visibly, our system of intellectual property rights, by providing temporary monopoly power to inventors, is meant to facilitate innovation. But often it has the opposite effect-inhibiting access to existing knowledge and making the production of new ideas more difficult. Moreover, by inhibiting competition, both innovation and access to the benefits of the advances that occur are reduced. These are arguments for keeping the scope and length of intellectual property rights limited.

Finally, markets are inherently bad at delivering the human element that is so important in medical care. Markets do not adequately reward the empathy and 
compassion that medical workers provide to their patients and, in fact, provide incentives to scrimp on them. If our technological choices are driven solely by the market, they will reflect the same bias and patient care is likely to be affected. It is essential that decision makers act to ensure that our technological choices reflect our human values. ${ }^{20}$

Contributors and sources: AK and JES wrote this article jointly by invitation from Sheng Wu at WHO. The two have collaborated on a series of papers investigating the effects of advances in $\mathrm{Al}$ on economic inequality, on which this analysis is based. All authors edited the manuscript before approving the final version. AK is guarantor.

Competing interests: We have read and understood BMJ policy on declaration of interests and have the following interests to declare: AK and JES are supported by a grant from the Institute for New Economic Thinking. AK serves as a senior adviser to the Partnership on Al's shared prosperity initiative working on related topics. JES is chief economist and senior fellow at the Roosevelt Institute working on a related theme.

Provenance and peer review: Commissioned; externally peer reviewed.

This collection of articles was proposed by the WHO Department of Digital Health and Innovation and commissioned by The BMJ. The BM/ retained full editorial control over external peer review, editing, and publication of these articles. Open access fees were funded by WHO.

Anton Korinek, associate professor ${ }^{1}$

Joseph E Stiglitz, professor ${ }^{2}$

${ }^{1}$ Department of Economics and Darden School of Business, University of Virginia, Charlottesville, VA, USA

${ }^{2}$ Columbia University, New York, NY, USA
Correspondence to: A Korinek akorinek@virginia.edu

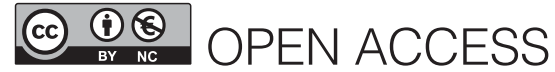

This is an Open Access article distributed under the terms of the Creative Commons Attribution IGO License (https://creativecommons.org/licenses/ by-nc/3.0/igo/), which permits use, distribution, and reproduction for non-commercial purposes in any medium, provided the original work is properly cited.

\section{D) Check for updates}

1 Basu S, Phillips RS, Phillips r, Peterson LE, Landon BE. Primary care practice finances in the United States amid the covid-19 pandemic. Health Aff (Millwood) 2020;39:1605-14. doi: 10.1377/ hlthaff.2020.00794

2 Bethune ZA, Korinek A. Covid-19 infection externalities: pursuing herd immunity or containment? NBER working paper w27009. 2020. https://www.nber.org/papers/w27009

3 Baldwin R. The globotics upheaval: globalization, robotics, and the future of work. Oxford University Press, 2019.

4 Metzl J. Al supported medical processes can help save human health care professionals. The Hill, 5 Apr 2020. https://thehill.com/opinion/ technology/491198-ai-supported-medicalprocesses-can-help-to-save-human-health-care

5 Torjesen I. Covid-19: Patients to use pulse oximetry at home to spot deterioration. BMJ 2020;371:m4151. doi:10.1136/bmj.m4151

6 Thornton J. The "virtual wards" supporting patients with covid-19 in the community. BMJ 2020;369:m2119. doi:10.1136/bmj.m2119

7 lacobucci G. Row over Babylon's chatbot shows lack of regulation. BMJ 2020;368:m815. doi:10.1136/ bmj.m815

8 Keynes JM. Economic possibilities for our grandchildren. In: Essays in persuasion. Harcourt Brace, 1931: 358-73.
9 Mokyr J, Vickers C, Ziebarth NL. The history of technological anxiety and the future of economic growth: is this time different?] Econ Perspect 2015;29:31-50. doi:10.1257/jep.29.3.31

10 Acemoglu D, Restrepo P. Automation and new tasks: how technology displaces and reinstates labor.J Econ Perspect 2019;33:3-30. doi:10.1257/jep.33.2.3

11 Korinek A. Labor in the age of automation and Al. Policy brief. Economists for Inclusive Prosperity, 2019.

12 Karabarbounis L, Neiman B. The global decline of the labor share. QJ Econ 2014;129:61-103. doi:10.1093/qje/qjt032

13 Cette G, Koehl L, Philippon T. Labor shares in some advanced economies. NBER working paper w26136 2019. https://www.nber.org/papers/w26136

14 Acemoglu D, Restrepo P. Robots and jobs: evidence from US labor markets. J Polit Econ 2020;128:2188244. doi:10.1086/705716

15 Korinek A, Stiglitz JE. Artificial intelligence and its implications for income distribution and unemployment. In: Agrawal A, Gans J, Goldfarb A.The economics of artificial intelligence. NBER, University of Chicago Press, 2019:349-90.

16 Korinek A, Ng DX. Digitization and the macroeconomics of superstars. Working paper. University of Virginia, 2019.

17 Autor D, Dorn D, Katz LF, Patterson C, Van Reenen J. The fall of the labor share and the rise of superstar firms. QJ Econ 2020;135:645-709. doi:10.1093/ qje/qjaa004

18 Korinek A, Stiglitz JE. Steering technological progress. Working paper. University of Virginia, 2021.

19 Shaw J, Rudzicz F, Jamieson T, Goldfarb A. Artificial intelligence and the implementation challenge. J Med Internet Res 2019;21:e13659. doi:10.2196/13659

20 Korinek A. Integrating ethical values and economic value to steer progress in artificial intelligence. In: Dubber M, Pasquale F, Das S, eds. The Oxford handbook of ethics of Al. Oxford University Press, 2020:463-79.

Cite this as: $B M J$ 2021;372:n367

http://dx.doi.org/10.1136/bmj.n367 